Basic Health Sciences

Poster

Abstract ID: 31

\title{
Determination of ultra-morphological changes of Trichophyton rubrum treated with hydroxychavicol
}

\author{
P.M Ridzuan ${ }^{\mathrm{a}}$ | Nasir Mohamad ${ }^{\mathrm{b}}$ | Salwani Ismail ${ }^{\mathrm{a}}$ | Nor Iza A. Rahman ${ }^{\mathrm{a}}$ | Mohd Adzim Khalili R. ${ }^{\mathrm{a}}$ | \\ Hairul Aini H. ${ }^{\mathrm{b}}$ | Zunariah B. ${ }^{\mathrm{b}} \mid$ M. H. Norazian ${ }^{\mathrm{b}}$ | Baharudin Roesnita ${ }^{\mathrm{c}}$ \\ ${ }^{a}$ Universiti Sultan Zainal Abidin Malaysia \\ ${ }^{b} K u l l i y y a h$ of Medicine, International Islamic University Malaysia \\ 'Hospital Tengku Ampuan Afzan, Kuantan, Pahang, Malaysia
}

Introduction: Trichophyton rubrum is a common pathogenic fungal species that is responsible for causing infection of human skin, hair and nail. The antifungal-resistant strains however, complicate the treatment regime. Hydroxychavicol $(\mathrm{HC})$ is one of the main compounds from the Piper betel leaf that have antifungal potential and its mechanism of action has yet to be studied. This study was carried out to determine the antifungal properties of $\mathrm{HC}$ against Trichophyton rubrum using transmission electron microscope (TEM) on gross and ultrastructure of Trichophyton rubrum hypha. Methods: Broth dilution method was used to determine the minimum inhibitory concentration (MIC) and minimum fungicidal concentration (MFC) of $\mathrm{HC}$ and miconazole (MI) against the Trichophyton rubrum (ATCC 28188). Trichophyton rubrum was treated with HC and MI at concentrations of $1.25,2.5,5$ and $10 \mathrm{mg} / \mathrm{mL}$ for $1,3,5$ and 7 days continuously. Results: The MIC results of the $\mathrm{HC}$ and $\mathrm{Ml}$ against Trichophyton rubrum were $0.00048 \mathrm{mg} / \mathrm{mL}$ and $0.000061 \mathrm{mg} / \mathrm{mL}$ respectively. MFC results showed $0.0019 \mathrm{mg} / \mathrm{mL}$ for $\mathrm{HC}$ and 0.000061 $\mathrm{mg} / \mathrm{mL}$ for MI. Microscopically, the fungi structures became more severely damaged at increasing treatment duration. The cell wall of the fungi treated with $\mathrm{HC}$ showed a rough surface, shrinkage and demolition similar to that of the Ml treated group. The fungi organelles were also demolished and disorganized. Conclusions: This study reveals that HC has the ability to inhibit Trichophyton rubrum growth and it has the potential to be an antifungal agent especially in treating dermatitis.

KEYWORDS: Piper betel, Trichophyton rubrum, hydroxychavicol, miconazole, antifungal 